\title{
EXPERIMENTAL METHODOLOGY FOR EVALUATING WORKPIECES SURFACE INTEGRITY IN DRY Turning OF AEROSPACE Alloys
}

\author{
J.M. Clares, J.M. Vazquez-Martinez, A. Gomez-Parra, F.J. Puerta, M. Marcos \\ ${ }^{a}$ University of Cádiz. Mechanical \& Industrial Design Dept., c/ Universidad de Cádiz, 10, \\ E-11510 Puerto Real (Cádiz), Spain
}

\begin{abstract}
Manufacturing procedures can affect the physicochemical properties of the developed elements, so in this contribution, an experimental methodology is design and development, focused on the assessment of the surface integrity in the dry turning of aerospace strategic alloys. In order to validate the proposed methodology, turning tests have been performed on cylindrical probes both aluminum as titanium alloys. Surface features have been evaluated through dimensional and geometrical measurements processes, together with the physicochemical evaluation of the material properties resulting from the machining process. Statistical analysis of the results promotes obtaining trends and behavior/predictive models from variations of turning parameters applied.
\end{abstract}

Keyword: Experimental methodology; Surface integrity; Aerospace alloys; Metrological evaluation; Dry turning
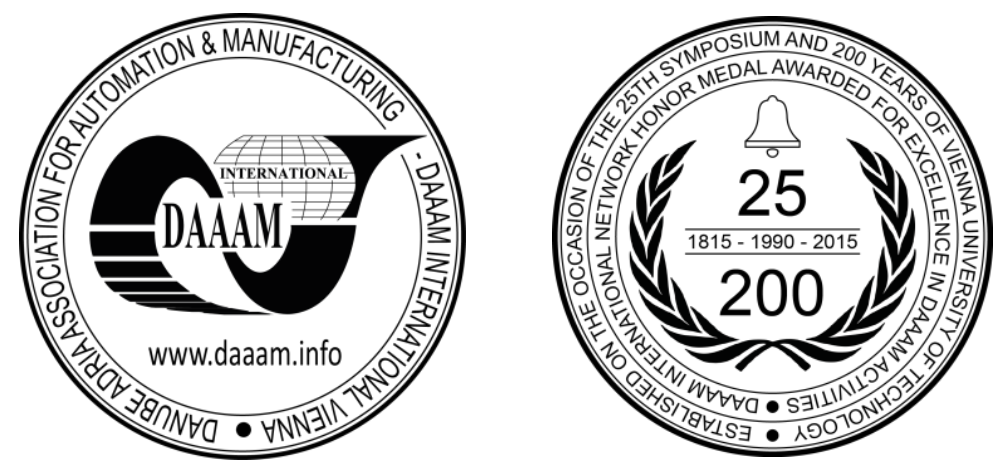

This Publication has to be referred as: Clares Rodriguez, J[ose] M[aria]; Vazquez Martinez, J[uan] M[anuel]; Gomez-Parra, A[lvaro]; Puerta Morales, F[rancisco] J[avier] \& Marcos, M[ariano] (2016). Experimental Methodology for Evaluating Workpieces Surface Integrity in Dry Turning of Aerospace Alloys, Proceedings of the 26th DAAAM International Symposium, pp.0849-0855, B. Katalinic (Ed.), Published by DAAAM International, ISBN 978-3-90273407-5, ISSN 1726-9679, Vienna, Austria

DOI:10.2507/26th.daaam.proceedings. 118 


\section{Introduction}

The International Air Transport Association (IATA) establishes that the most of causes of aeronautical accidents are based on the loss of control in flight of the aircraft. This fact is mainly caused by stress or corrosion-stress phenomena $[1,2]$.

Manufacturing procedures can affect the physicochemical properties of developed elements. Therefore the establishment of relationships is required between the manufacturing process and the final properties of the pieces, which affect to their functional behaviour. On the other hand, manufacturing process must maintain economical and energetic efficiency and it should not affect negatively the environment.

In this sense, the concept of performance in a manufacturing process has been extended in recent studies $[3,4]$, taking into account these four viewpoints. Furthermore, such evaluation has been proposed through the mass centre of a diamond -so called Four Axis of Manufacturing- where the Environmental, Energetic, Economic, and Functional, with corresponding weights, Figure $1[3,4]$.

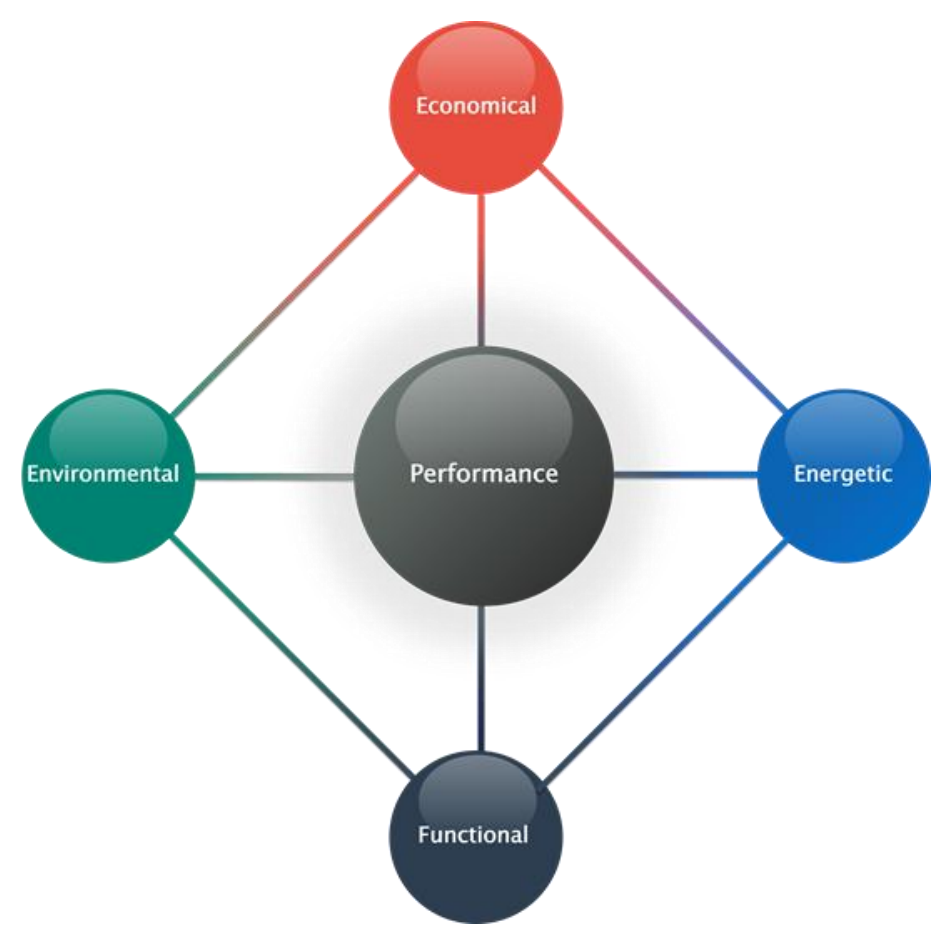

Fig. 1. Four Axis of Manufacturing. Adapted from [3,4]

Functional performance is directly related to surface integrity [5-9], which keeps great significance on the improvement and maintenance of risk components. This evaluation requires the study of geometrical parameters (macrogeometry and microgeometry) and/or physicochemical variables (microhardness, residual stresses, microstructure, etc.), and these parameters can serve as a basis for analyzing the functional performance of the machining elements.

Although turning is not one of the most used applications in the aerospace field, especially when is compared with drilling, it is an important process involved for example in the manufacture of great relevance structural components such as bolts. On the other hand, the lack of complexity of process makes it suitable for the design of this methodology, also allowing extrapolate the obtained results to complex machining processes.

However, despite everything discussed above, it can hardly be found any work in the literature which studies are carried out combining all the features, variables and exposed conditions to determine the influence of machining in the functional response of a material [10-14]. Furthermore, the methodology described in this paper is used to obtain accurate results in the development thereof.

\section{Experimental procedure}

In present work, the design and development of a methodology has been carried out in order to assessment the surface integrity obtained in dry turning processes of strategic alloys used in the aerospace industry, Figure 2.

Looking at this figure, it can be observed as, after selecting and preparing the test material samples, turning process, with a specific setting for each test, was performed. Subsequently, using metrological procedures, dimensional, geometrical and physicochemical characterizations of the machined samples were performed, Figure 2. 
The proposed methodology allows to reduce defects in manufactured parts, decreasing costs and improving the performance of processes involved.

\subsection{Material}

The methodology designed in this study provides in its development and implementation the use of the main alloys used in the manufacturing of aircrafts, such as aluminum and titanium alloys. Nevertheless, in order to simplify the validation in the evaluation process of surface integrity, the used material for turning process has been the aluminum-copper UNS-A92024-T351 alloy.

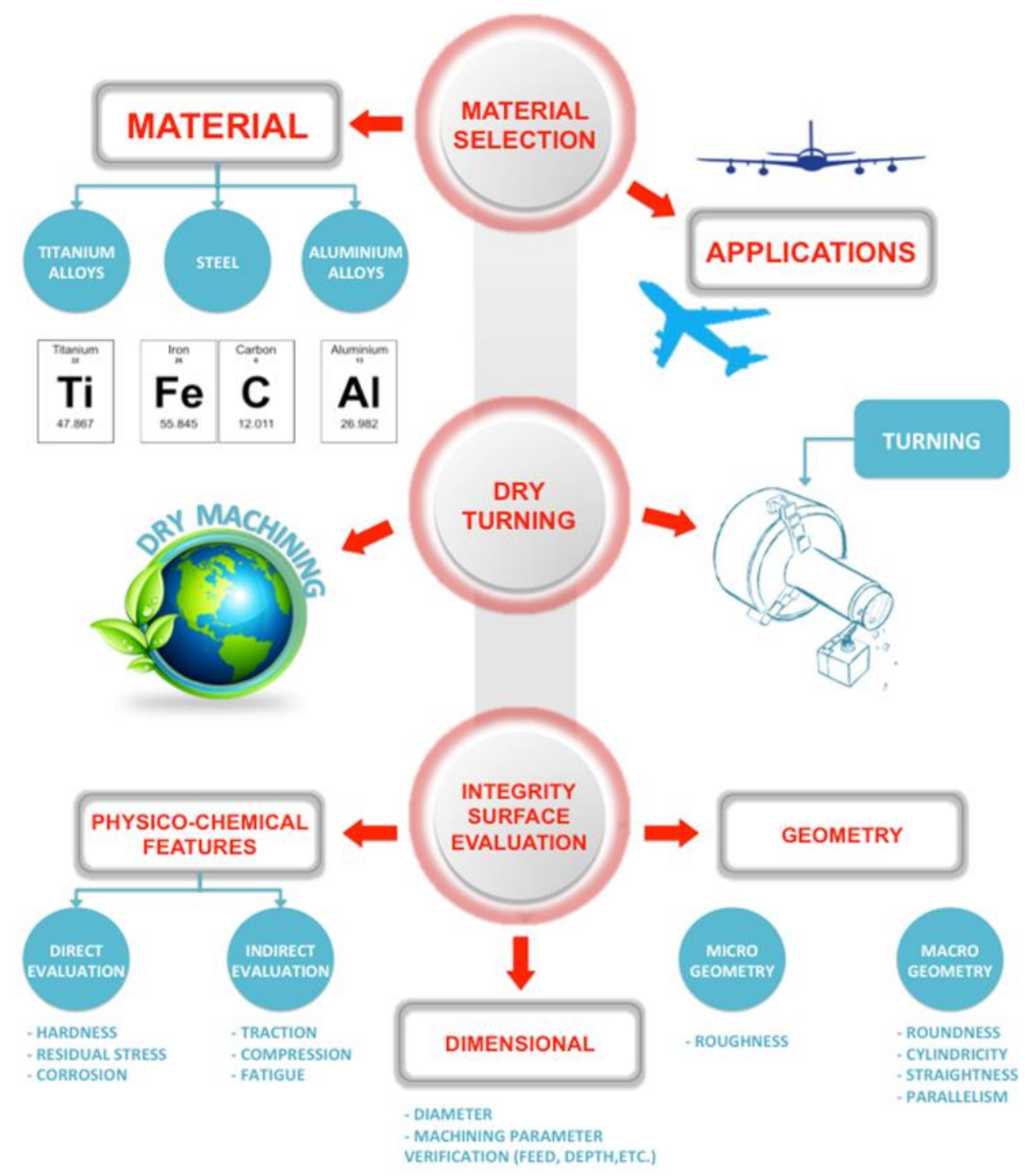

Fig. 2. Methodology for the assessment of surface integrity

\subsection{Turning tests}

Dry turning tests were carried out on cylindrical samples of aforementioned aluminum alloy, with machining parameters as shown in Table 1. A conventional lathe was used for this purpose. The absence of cutting fluids allows promoting the environmental sustainability of the process.

Neutral turning inserts ISO DCMT 11T3308 were used as cutting tools, Figure 3.

\begin{tabular}{cccc}
\hline $\mathrm{V}[\mathrm{m} / \mathrm{min}]$ & $\mathrm{F}[\mathrm{mm} / \mathrm{min}]$ & $\mathrm{d}[\mathrm{mm}]$ & $\mathrm{S}\left[\mathrm{min}^{-1}\right]$ \\
\hline 200 & $0,03-0,20$ & 0,50 & 588,00 \\
\hline
\end{tabular}

Table 1. Turning tests parameters 


\subsection{Dimensional measurement}

In order to assess the dimensional variation caused by machining on the studied samples, the measurements of the initial dimensions of cylindrical aluminium alloy samples were performed using a horizontal coordinate measure machine. At the same time the diameters of the samples were also analyzed through a set of sections evenly spaced along the axial length of the cylinder in $0^{\circ}$ and $90^{\circ}$. The measurement on perpendicular sections allows detecting geometrical deviations at different heights of machining sample.

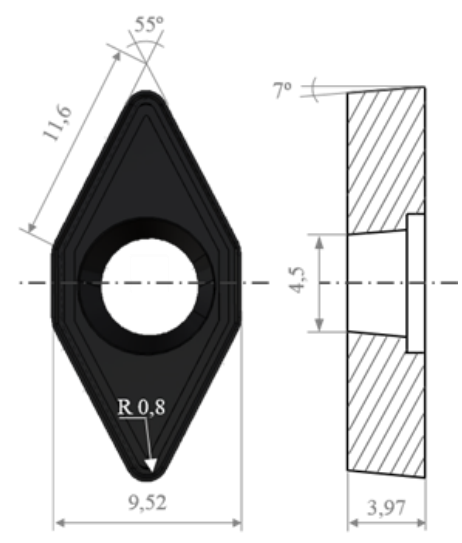

Fig. 3. Turning tests tool

\subsection{Geometrical evaluation}

Geometrical analysis of samples presents two different types of evaluation depending on the magnitude of geometric deviations obtained. Thus, an evaluation of surface integrity was carried out from a microgeometrical point of view, focusing the analysis on the surface finish after the machining process. On the other hand, a macrogeometrical evaluation of the samples was carried out studying in greater depth form deviations produced during turning process.

The surface integrity evaluation of the machining samples from a microgeometrical viewpoint is based on the measurement and analysis of the surface finish obtained after turning process.

Microgrooves are generated which results in a variable roughness, mainly due to the displacement of the tool on the surface of the cylindrical samples during machining process, with large influence on machining parameters applied.The equipment employed for the measurement of surface finish consists in a topographic roughness device MAHR Perthometer Concept PGK120.

The curved shape of the cylindrical surface of the sample may hinder the obtaining topographic maps roughness of large enough areas, so in this case, measurement of individual profiles is recommended (Figure 4).

To obtain an accurate description of the predominantly roughness of samples, a set of profile measurements were carried out of different sections on sample height, rotating a defined angle value for each generatrix studied. Measurements following the indications described in the applicable standards were performed [15], taking more widespread roughness parameters in these types of studies such as Ra and Rz.

The macrogeometrical assessment is mainly based on determining form deviations caused in turning process of the UNS A92024 alloy samples. Measurements of these deviations were carried out by a geometry measure machine MAHR MMQ44, classifying in circular and axial deviations due to defects in the surface of the cylindrical specimen (Figure 5).

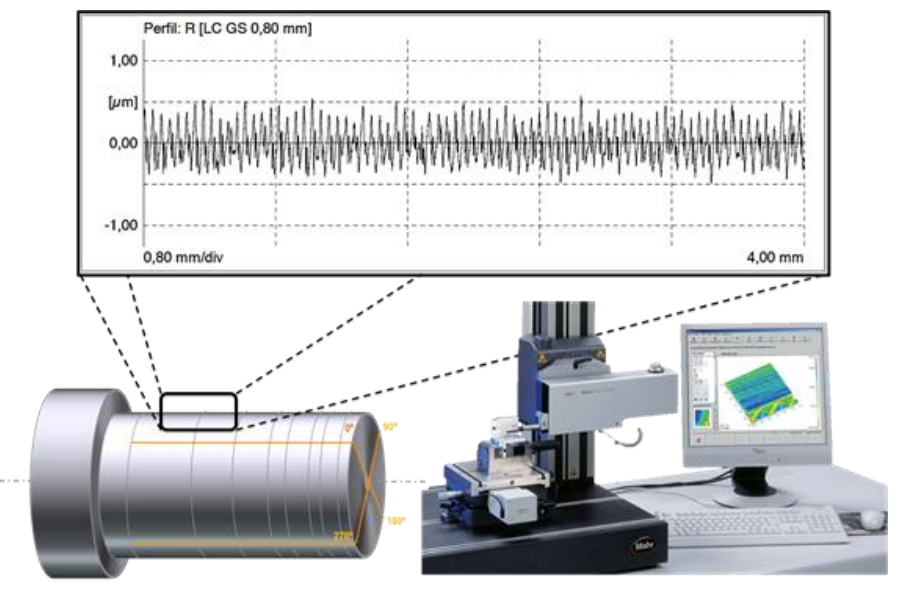

Fig. 4. Microgeometrical analysis 
Circular deviations analyzed are composed of roundness measurements on a range of sections along the surface of the sample, evenly distributed along the longitudinal axis thereof and cylindricity measurements around the outer contour of the sample, determined from circular measurements used in the evaluation of roundness deviations. Furthermore, the axial deviations are based on linear measurements on different generatrix of the sample, determining the straightness deviations and parallelism between the rotation axis of the cylindrical test probes and a set of generatrix distributed in the material surface.

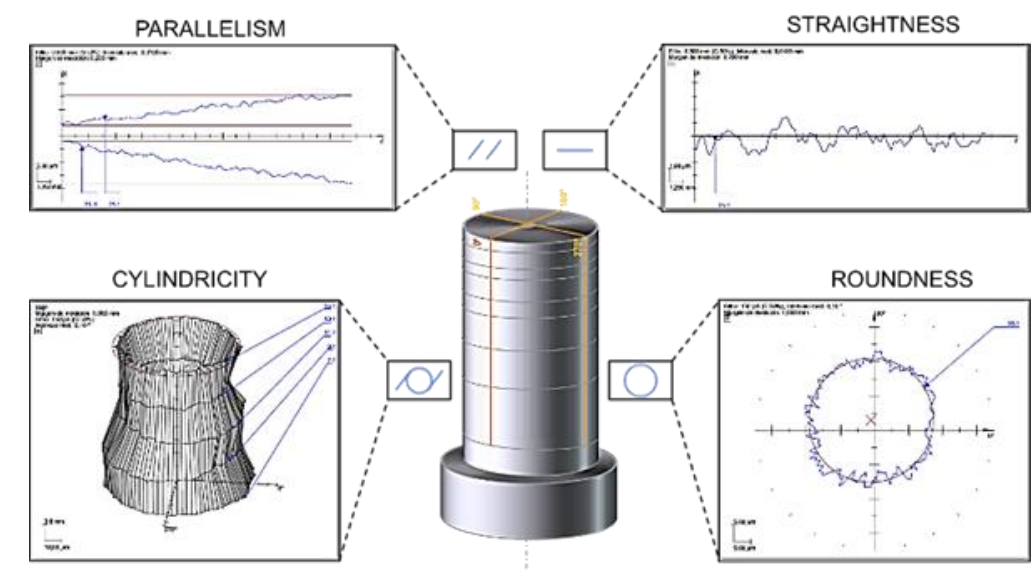

Fig. 5. Macrogeometrical analysis

\subsection{Physicochemical evaluation}

The physicochemical surface integrity assessment have been carried out by direct analysis through the studied material, or by means of indirect methods, where external samples or replicas for specific material properties test are required.

The direct evaluation of the sample involves perform microhardness measurement, with the aim to obtain information about the influence of machining on the surface hardness and its evolution based on the variation of the turning parameters. Furthermore, in order to evaluate the residual stresses in the material due to the action of the machining process, measurements of residual stress through hole-drilling technique have been developed. Through this analysis, the value of residual stresses of the material can be observed at several depths of the machined surfaced in two axis (Figure 6).

For indirect evaluation of the mechanical properties of the material, the design of new samples is required. This allows performing tensile, compression and fatigue tests of the machined alloy.

Other evaluations, such as stress-strain tests, fatigue, corrosion, stress corrosion cracking, etc, have been included in the methodology, although they have not been studied in the validation process included in this paper.

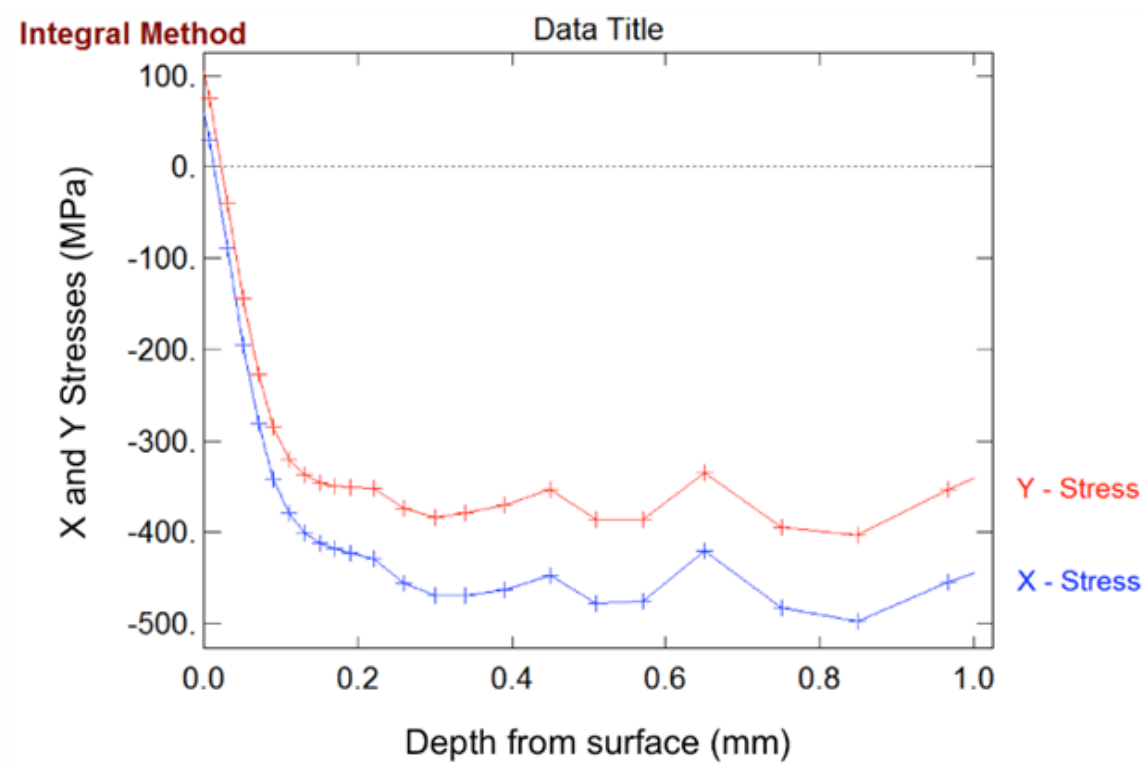

Fig. 6. Residual stresses results 


\section{First results and discussion}

Through the development of the procedures described in the proposed methodology, accurate results can be obtained for the selected parameters of surface integrity, ensuring in this way the validity of the conducted study (Figure 7).

From the data obtained in the measurements described above, statistical analyses of the results were conducted, which allows observing different behavior and trends of the material and machining conditions. In this aspect, the average, maximum and minimum values of the measurements have been obtained as well as the standard deviation of the data.

The study of the measurements results enables the generation of predictive behavior models, favoring the selection of most suitable machining parameters to specific applications of manufactured components.

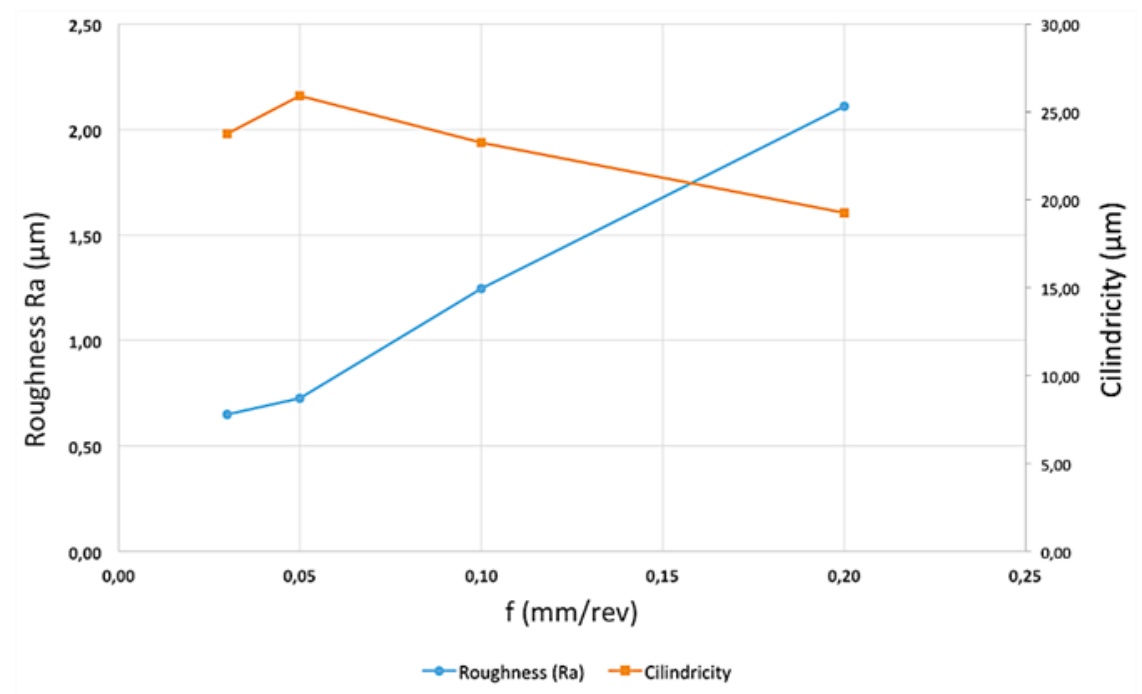

Fig. 7. Measurement results

\section{Conclusion}

The design and development of an experimental methodology for the evaluation of the surface integrity of strategic materials in the aerospace industry has been carried out. Such methodology, aims planning and studying several procedures used in the analysis of the properties and magnitudes involved in the improvement of the manufacture of machined components.

Statistical analysis of the results promotes to obtain trends and behaviour/predictive models from variations of turning parameters applied.

\section{Acknowledgements}

This work has received financial support from the Spanish Government through the Project DPI2011-29019, from the Andalusian Government and from the European Union (PROJECT DIANNA).

\section{References}

[1] IATA. Safe Security Results 2013. Report No14, 2014. [2] W. Strunk Jr., E.B. White, The Elements of Style, third ed., Macmillan, New York, 1979

[2] IATA. Final Safety Report 2013, 2013

[3] A. Gómez-Parra, M. Álvarez-Alcón, J. Salguero, M. Batista, M. Marcos, Analysis of the evolution of the Built-Up Edge and Built-Up Layer formation mechanisms in the dry turning of aeronautical aluminium alloys. Wear 302, 2013, pp. 1209-1218

[4] J. Salguero, Analysis, evaluation and improvement proposals of high speed machining performance of aluminium alloys (in Spanish), Phd Thesis, Cádiz, Spain, 2013

[5] W.P. Koster, M. Field, L.J. Fritz, L.R. Gatto, J.F. Kahles, Surface integrity of machined structural components. AFML-TR-70-11, 1970

[6] J.P. Davim, Surface Integrity in Machining, Springer, 2010

[7] R. M'Saoubi, J.C. Outeiro, H. Chandrasekaran, O.W. Dillon Jr, I.S. Jawahir, A review of surface integrity in machining and its impact on functional performance and life of machined products. Int. J. Sustainable Manufacturing 1, 2008, pp. 203-236 
[8] I.S. Jawahir, E. Brinksmeier, R. M'Saoubi, D.K. Aspinwall, J.C. Outeiro, D. Meyer, D. Umbrello, A.D. Jayal, Surface integrity in material removal processes: Recent advances. CIRP Ann. Manuf. Technol. 60, 2011, pp. 603626

[9] G. Rotella, O.W. Dillon Jr., D. Umbrello, L. Settineri, I.S. Jawahir, Finite element modeling of microstructural changes in turning of AA7075-T651 Alloy. Journal of Manufacturing Processes 15, 2013, pp. 87-95

[10] D. Carou, E.M. Rubio, C.H. Lauro, J.P. Davim, Experimental investigation on surface finish during intermittent turning of UNS M11917 magnesium alloy under dry and near dry machining conditions. Measurement 56, 2014, pp. 136-154

[11] G. M. Assis Acayaba, P. Muñoz de Escalona, Prediction of surface roughness in low speed turning of AISI316 austenitic stainless steel. CIRP Journal of Manufacturing Science and Technology 333, 2015

[12] P.Sam Paul, A.S. Varadarajan, R. Robinson Gnanadurai, Study on the influence of fluid application parameters on tool vibration and cutting performance during turning of hardened steel.. Engineering Science and Technology, an International Journal, 2015

[13] H.H Shahabi, M.M. Ratnam, Simulation and measurement of surface roughness via grey scale image of tool in finish turning. Precission Engineering, 2015

[14] Junyun Chen, Qingliang Zhao, A model for predicting surface roughness in single-point diamond turning. Measurement 69, 2015, pp. 20-30

[15] UNE-EN ISO 4288:1998, Geometrical Product Specifications (GPS). Surface texture: Profile method. Rules and procedures for the assessment of surface texture, AENOR, 1998 